Revista Colombiana de Educación 56 


\begin{abstract}
Revista Colombiana de Educación. --N. ${ }^{\circ} 1$
(Ene.,-jun., 1978)_. -- Bogotá, Colombia :

UPN.DGP.CIUP, 1978.

Semestral

ISSN 0120-3916

1. Educación. Publicaciones Periódicas. 2. Colombia. Educación. 3 Investigación Educativa.

I. Universidad Pedagógica Nacional. División de Gestión de Proyectos. Centro de Investigaciones.
\end{abstract}

\begin{abstract}
Revista indexada por Colciencias en categoría B y por los índices internacionales: Internacional Bibliography of the Social Sciences (IBSS); Educational Research Abstracts (ERA); Índice de Revistas de Educación Superior e Investigación educativa (IRESIE); Sistema Regional de información en línea para Revista Científicas de América Latina, el Caribe, España y Portugal (LATINDEX), Catálogo de Citas Latinoamericanas en Ciencias Sociales (CLASE), de la Universidad Nacional Autónoma de México; Biblioteca Digital OEl; Ulrich Periodicals Directory; Handbook of Latinamerican Studies of Library of Congress
\end{abstract}

\section{ISSN 0120-3916}

Copyright:

Los artículos de este número pueden ser utilizados citando la fuente.

Tarifa Postal reducida por Resolución 2244

de septiembre de 1990 de la Administración Postal.

División Gestión de Proyectos, Centro de Investigaciones Universidad Pedagógica Nacional (DGP-CIUP) Avenida Calle 127 N. ${ }^{\circ} 11-20$, Bogotá D.C Colombia Datos de contacto: (057-1) 6156531

rce@pedagogica.edu.co

rceupn@gmail.com

Responsable del canje:

Miriam Aixa González

División de Biblioteca y Recursos Bibliográficos

mgonzale@pedagogica.edu.co

Teléfono (057-1) 5941894, ext. 175

Suscripción Nacional e Internacional:

Impresión

Editorial Kimpres Ltda.

Bogotá, 2009
La Revista Colombiana de Educación es una publicación semestral del Centro de Investigaciones de la Universidad Pedagógica Nacional que data de 1978 y ha pretendido ser una publicación de referencia para los estudiosos de la educación y la pedagogía. El público al que se dirige contempla a los especialistas en temáticas educativas y pedagógicas, al magisterio en general y a estudiantes universitarios de pregrado $y$ posgrado de las áreas de educación, ciencias sociales y humanidades.

La responsabilidad de las opiniones que se exponen en los artículos corresponde a sus autores. 


\section{Revista Colombiana de Educación 56 \\ Bogotá - Colombia Primer semestre de 2009}

\section{Rector \\ Oscar Armando Ibarra Russi \\ Vicerrectora académica \\ Clara Inés Chaparro Susa}

Vicerrector de Gestión Universitaria

Gerardo Andrés Perafán Echeverri

División Gestión de Proyectos, CIUP

Yolanda Ladino Ospina

Coordinador general

Christian Hederich Martínez

Editor temático

Édgar Orlay Valbuena Ussa

Preparación editorial

Universidad Pedagógica Nacional

Fondo Editorial

Coordinador

José Ignacio Curcio Penen

Corrección de estilo

Germán David Barbosa C.

Diagramación

Fredy Johan Espitia Ballesteros

Asistencia editorial

Mary Lache, Supernumerario DGP-CIUP 


\section{Comité Editorial}

Alberto Martínez Boom, Martha Cecilia Herrera Cortés, Adolfo León Atehortúa Cruzy Christian Hederich Martínez, Universidad Pedagógica Nacional; Águeda Bittencourt, Universidad de Campinas, Brasil; Emilio Tenti Fanfani, Instituto Internacional de Planeamiento de la educación, IIPE, Unesco, Argentina; Aimer Granados García, Universidad Autónoma Metropolitana, Sede Cuajimalpa, México, y Mariano Narodowski, Universidad Torcuato Di Tella, Argentina.

\section{Arbitraje}

Han colaborado como árbitros para este número los doctores: Neus Sanmartí, de la Universidad Autónoma de Barcelona, España; Margarita García Astete, de la Universidad Nacional de Educación a Distancia, Uned, España; Nuri Martha Trigo Boix, de la Universidad Autónoma Metropolitana, México; María Teresina Bellanda Galuch, de la Universidad Estadual de Maringá, Brasil; María Charrier, de la Universidad del Mar del Plata, Argentina; Elsa Noemí Meinardi y Agustín Adúriz Bravo, de la Universidad de Buenos Aires, Argentina; Alicia Benarroch Benarroch y Javier Rodríguez Alcázar, de la Universidad de Granada, España; Pilar Aznar Minguet, Joan Josep Solaz-Portolés y Daniel Gil Pérez, de la Universidad de Valencia, España; Juan José Palacios Burgos, de la Universidad de Alicante, España; Eloy López Meneses, de la Universidad de Extremadura, España; José Antonio Caride Gómez y José Mendoza Rodríguez, de la Universidad de Santiago de Compostela, España; Mario Quintanilla, de la Pontificia Universidad Católica de Chile, Chile; Andoni Garritz Ruiz, de la Universidad Nacional Autónoma de México; Vicente A. Talanquer, de la Universidad de Arizona, Estados Unidos; Ángela Stella Camacho Beltrán, de la Universidad de Los Andes, Colombia; Clara Helena Sánchez Botero y Diana Obregón Torres, de la Universidad Nacional de Colombia; María Elena
Giraldo Ramírez, de la Universidad Pontificia Bolivariana, Colombia; Carlos Eduardo Vasco Uribe, del Centro de Investigaciones y Estudios Avanzados, Cinde, Universidad de Manizales, Colombia; Carlos Arturo Soto Lombana y Marco Antonio Giraldo Cadavid, de la Universidad de Antioquia, Colombia; Oscar Eugenio Tamayo Alzate, de la Universidad de Manizales, Colombia; Héctor Elí Rizo Moreno, de la Universidad Autónoma de Occidente, Colombia; Miguel Hugo Corchuelo Mora, de la Universidad del Cauca, Colombia; Álvaro Perea, de la Universidad del Valle, Colombia; Giovanni Marcello Lafrancesco Villegas, de la Corporación Internacional Pedagogía y Escuela Transformadora, Coripet, Colombia; Margie Noemí Jessup Cáceres, Rosalba Pulido de Castellanos, Yolanda Ladino Ospina, Pablo Fernando Páramo Bernal, Luis Enrique Salcedo Torres, Pedro Nel Zapata Castañeda y Carlos Arturo Sierra Diosa, de la Universidad Pedagógica Nacional, Colombia. 


\section{CONTENIDO}

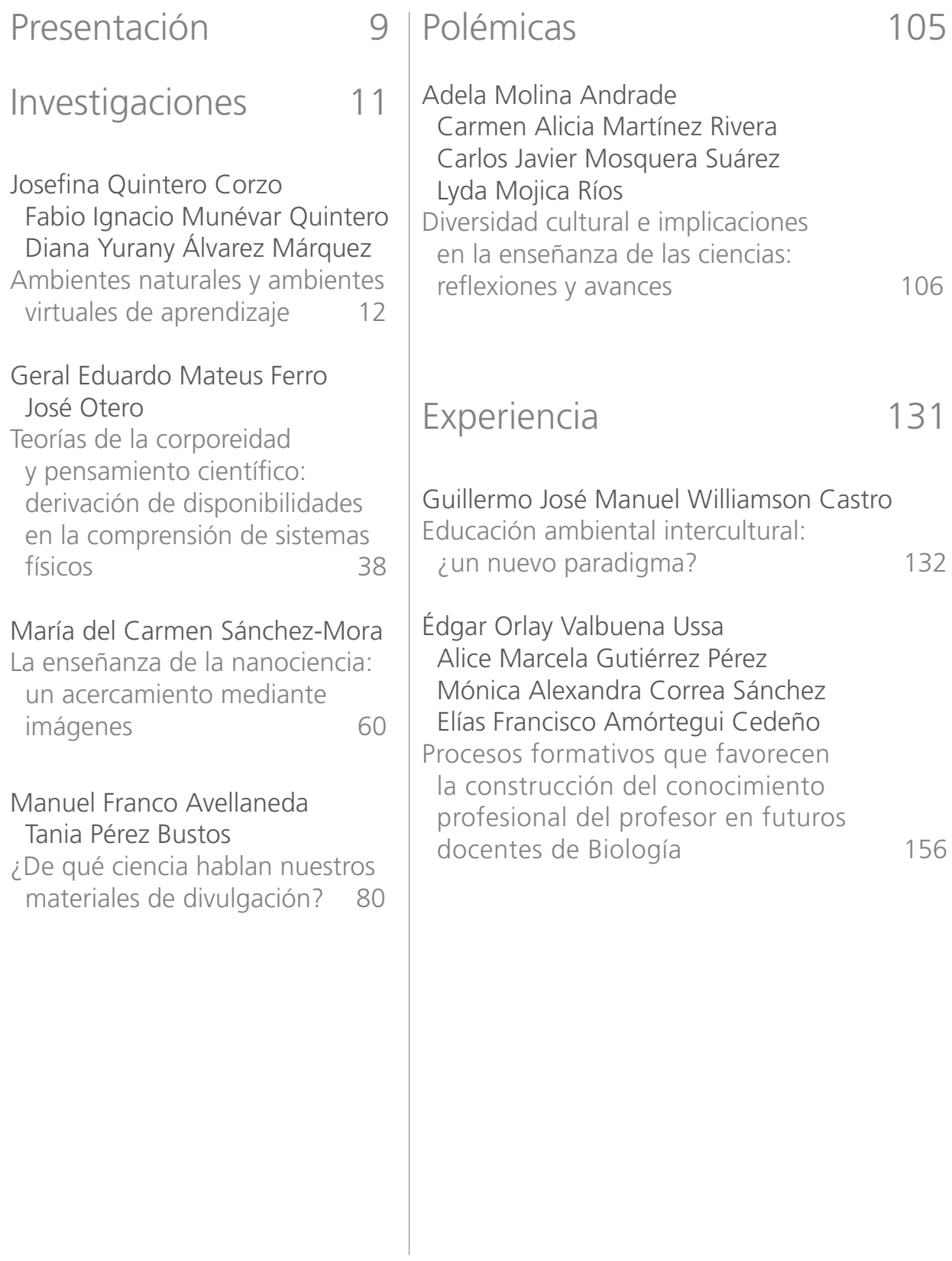

[5] Revista Colombiana de Educación, N. ${ }^{\circ}$ 56. Primer semestre de 2009, Bogotá, Colombia. 



\section{CONTENT}

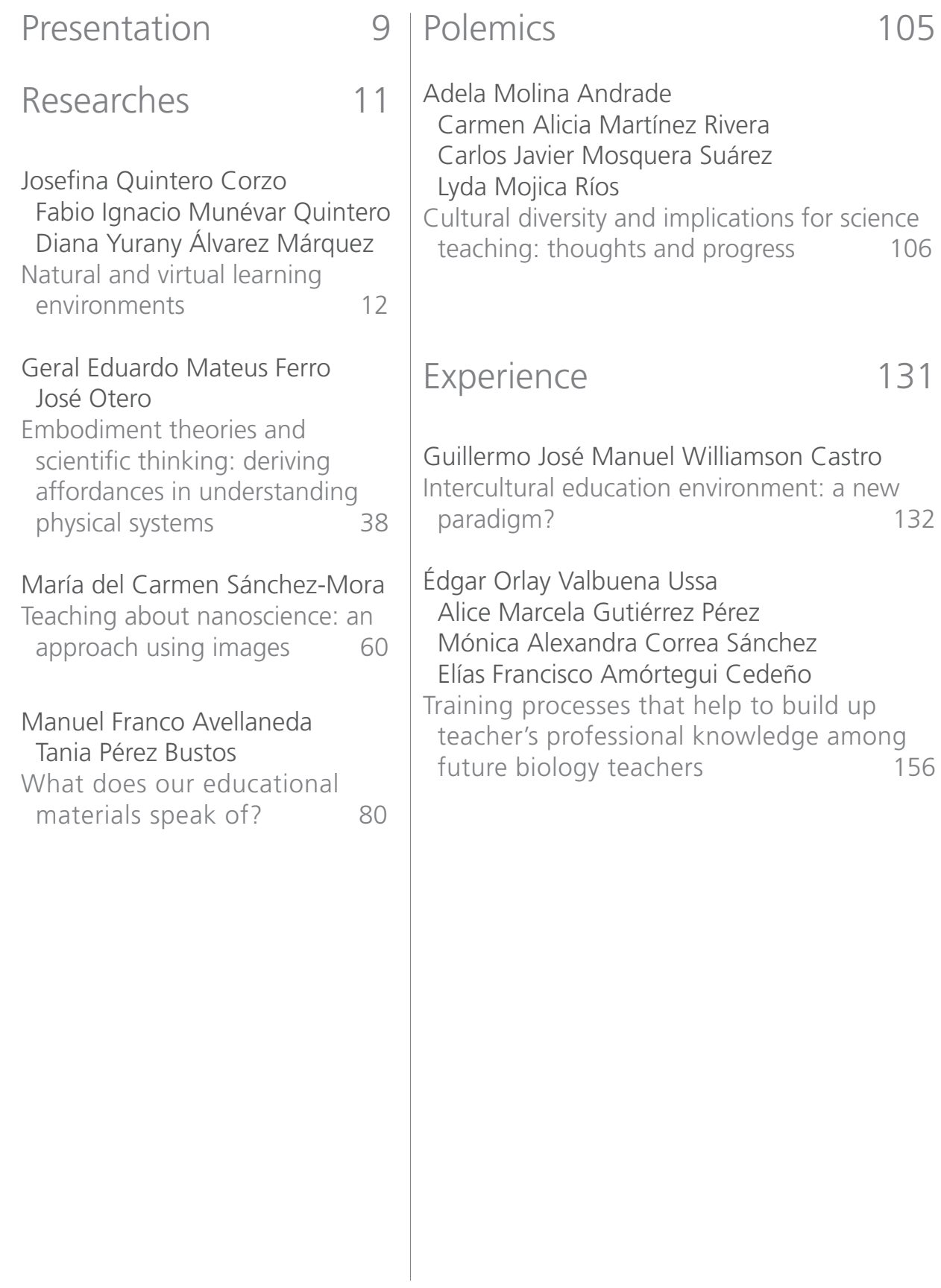





\section{PRESENTACIÓN}

El presente número de la Revista Colombiana de Educación constituye un monográfico dedicado a la educación en ciencias y tecnologías. Los artículos que se publican corresponden a estudios realizados por diferentes grupos de investigación, nacionales e internacionales, que responden problemáticas educativas relevantes, enmarcadas en los siguientes asuntos: aprendizaje, materiales educativos, formación docente y diversidad cultural.

Tres de los trabajos corresponden al primer asunto, dos se relacionan con aspectos relativos a estrategias para el aprendizaje de las Ciencias y las Tecnologías. La investigación de Sánchez-Mora trata el uso de imágenes en la enseñanza de conceptos referentes a objetos y procesos de orden microscópico, profundizando en los obstáculos para la comprensión de las nanoescalas y la representación icónica en la enseñanza de las ciencias. Quintero, Munévar y Álvarez, presentan el diseño, la validación, la aplicación y el análisis de un material propio del ambiente virtual para el aprendizaje de conceptos sobre educación ambiental. En la investigación de Mateus y Otero se presentan los resultados del diseño y la aplicación (en el ámbito español) de dos experimentos, referentes a conceptos físicos, para facilitar la derivación de disponibilidades científicas.

Por otra parte, Franco y Pérez analizan un material educativo diseñado por un centro interactivo de ciencia y tecnología colombiano. Para ello, tienen como punto de referencia las visiones deformadas sobre la ciencia. Valbuena et al., presentan el análisis de las implicaciones en la construcción del "Conocimiento Profesional" de dos estrategias (el diseño de unidades didácticas y la formulación de proyectos pedagógicos) en un programa de formación inicial para profesores de Biología, en el contexto colombiano. 
Dos de los artículos tratan un aspecto más metadisciplinar: la diversidad cultural en relación con la enseñanza de las ciencias y las tecnologías. Molina et al., presentan un panorama teórico de lo que implica la polisemia de la diversidad cultural y las relaciones con la educación, abordando el problema de la homogenización en la escuela. Por su parte, Williamson presenta el análisis de un programa de Educación Ambiental chileno en el que participan diferentes grupos culturales (incluidos indígenas). 